\title{
Evolución y tendencias de la investigación en comunicación sobre epidemias y pandemias en el ámbito internacional
}

\author{
Evolution and trends in communication research about \\ epidemics and pandemics at the international level
}

\author{
Ortiz Núñez, R. y Stable Rodríguez, Y. ${ }^{1}$ \\ Recibido: 30-09-2020 - Aceptado: 28-01-2021 \\ https://doi.org/10.26441/RC20.1-2021-A10
}

\begin{abstract}
RESUMEN: La investigación sobre comunicación en tiempos de epidemias y pandemias constituye un factor trascendental en la prevención, tratamiento y recuperación. El estudio que se presenta, analiza el comportamiento de la investigación en comunicación sobre epidemias y pandemias a través de la producción científica registrada en la base de datos Scopus. Se emplean indicadores para evaluar las tendencias generales de publicación a nivel de país, instituciones, autores, revistas y artículos. Se examinan los temas preponderantes y su evolución temporal, así como, la evolución en los grupos y frentes de investigación asociados. Los resultados muestran una tendencia al crecimiento de publicaciones con una mayor concentración en el 2020. El número de publicaciones por países, instituciones, autores y revistas es discreto, por lo que, es un área de conocimientos que requiere mayor investigación científica y colaboración internacional. Se identificaron 5 grandes grupos temáticos, principales focos emergentes de investigación, relacionados con la comunicación de salud durante epidemias, las actitudes sociales hacia la salud, la comunicación durante la influenza $A$ H1N1 y la pandemia COVID-19 y la información epidemiológica en redes sociales. Los puntos críticos de investigación en el campo durante los 30 años registrados en la base de datos Scopus permiten inferir, que la comunicación sobre epidemias y pandemias debe convertirse en foco de la investigación en el área de comunicación de riesgos en un futuro próximo.
\end{abstract}

Palabras clave: investigación en comunicación; epidemias; pandemias; comunicación de riesgo; comunicación en salud; producción científica; Scopus.

ABSTRACT: Communication research in times of epidemics and pandemics is an important factor in prevention, treatment and recovery. The study presented analyzes the behavior of communication research about epidemics and pandemics through the scientific production registered in the Scopus database. Indicators are used to assess general publication trends at the country, institutional, author, journal and article level. The prevailing themes and their evolution over time are examined, as well as the evolution in the groups and associated research fronts. The results show a trend towards the growth of publications with a higher concentration in 2020. The number of publications by countries, institutions, authors and journals is discrete, therefore, it is an area of knowledge that requires greater scientific research and international collaboration. Five major thematic groups, main emerging research focuses, related to health communication during epidemics, social attitudes towards health, communi-

\footnotetext{
${ }^{1}$ Roelvis Ortiz Núñez es Doctorando en Ciencias de la Información, Máster en Desarrollo Local y Licenciado en Ciencias de la Información (Cuba). Docente e investigador del Instituto de Información Científica y Tecnológica, La Habana, Cuba. Especialista Principal del Observatorio Científico, Tecnológico y de Innovación. roelvis.ortiz@idict. cu, https://orcid.org/0000-0002-7069-1439

Yudayly Stable Rodríguez es Doctora en Ciencias por el Instituto Superior de Tecnologías y Ciencias Aplicadas de la Universidad de la Habana y Máster en Gestión Universidad. Es investigadora Titular en el Instituto de Información Científica y Tecnológica y profesora Auxiliar en la Universidad de la Habana. yuly@idict.cu, https://orcid. org/0000-0002-4635-7991
} 
cation during influenza A H1N1 and the COVID-19 pandemic, and epidemiological information on social networks were identified. The critical points of research in the field during the 30 years recorded in the Scopus database allow us to infer that communication about epidemics and pandemics should become the focus of research in the area of risk communication in the near future.

Keywords: communication research; epidemics; pandemics; risk communication; health communication; scientific production; Scopus.

\section{Introducción}

En los últimos años, una serie de brotes de enfermedades infecciosas como el ébola, el zika, la influenza y el dengue en todo el mundo han arrojado luz sobre la importancia de las estrategias de comunicación efectivas con respecto a dichas enfermedades (Parmer et al., 2016). Las pandemias del pasado, como el síndrome respiratorio agudo severo (SARS) de 2003 y el H1N1 en 2009, han tenido impactos significativos en la vida de las personas, las actividades socioeconómicas y el movimiento de la población (Xiao, Tang \& Wu, 2015). COVID-19 también presenta impactos similares, pero su propagación es aún más rápida (Wilder-Smith, Chiew \& Lee, 2020).

Una pandemia requiere acciones inmediatas a gran escala y un cambio en el comportamiento del público para combatir la rápida propagación de la enfermedad (Cummings, 2009). La comunicación eficaz de la epidemia es crucial para informar al público sobre las últimas actualizaciones de la enfermedad, motivarlos a adoptar medidas preventivas para minimizar la transmisión y asegurarles que es posible manejar la situación (Jones, Waters, Holland, Bevins \& Iverson, 2010; de Vries, 2016; Strekalova, 2017; Liwei, Li \& Chen, 2020).

En efecto, la comunicación está jugando un papel central en la protección de la salud de las personas en todo el mundo en caso de brotes de esas epidemias o pandemias. Y es un factor importante en la forma en que las autoridades internacionales y nacionales están abordando esas epidemias y pandemias, cuyas consecuencias para las poblaciones vulnerables dependerán en parte, de la eficacia de las comunicaciones sobre riesgos para la salud. Las estrategias efectivas para la comunicación de riesgos sanitarios son esenciales para proteger la salud pública, en tales circunstancias, la comunicación debe instruir, informar y motivar un comportamiento de autoprotección apropiado, generar seguridad y disipar rumores.

Con un papel ampliado en la planificación y respuesta a una pandemia, los procesos de comunicación pueden contribuir a que el público se adapte a las circunstancias cambiantes o la incertidumbre durante epidemias, facilitar la anticipación de eventos sorprendentes, crear un diálogo entre las poblaciones potencialmente afectadas y gestores de riesgos, y fomentar un entorno de confianza mutua.

Existen varios estudios sobre la comunicación de epidemias y pandemias, principalmente en los medios tradicionales (Sandell, Sebar \& Harris, 2013; Ophir, 2018), lo que sugiere que el público se informa de los riesgos para la salud asociados con la pandemia a través de los medios de comunicación (Frewer, Miles, Brennan, Kuznesof, Ness \& Ritson, 2002; Roche \& Muskavitch, 2003), esto afecta la forma en que responden a la epidemia o pandemia. En los últimos años, las redes sociales han desempeñado un papel cada vez más importante en la promoción de la comunicación de riesgos para la salud durante una epidemia (Househ, 2016; Gui et al., 2018).

En efecto, la investigación sobre comunicación durante epidemias y pandemias constituye uno de los objetivos más importantes de los profesionales de la comunicación, de la salud y de gobiernos, y en la actualidad existe una producción intelectual, que refleja el surgimiento de una masa crítica de profesionales, que sentaron las bases para que floreciera la investigación de un factor trascendental en la prevención de enfermedades infecciosas. 
El abordaje de las investigaciones que desde las metrías de la información de alguna manera se han concentrado en este espacio de conocimiento constituyen antecedentes inmediatos del presente trabajo. Estas investigaciones han analizado y representado el comportamiento de la producción científica sobre comunicación, medios tradicionales, redes sociales y comunicación de riesgos (Bellón Saameñoa \& Martínez Cañabateb, 2001; Hugh Feeley, 2008; Castillo \& Carretón, 2010; Castillo-Esparcia, Peña Timón y Mañas Valle, 2014; Marí-Sáez \& Ceballos-Castro, 2015; Baladrón-Pazos, Manchado-Pérez \& Correyero-Ruiz, 2017; Montero-Díaz, Cobo, Gutiérrez-Salcedo, Segado-Boj \& Herrera-Viedma, 2018; Soós \& Kiss, 2020; Segado-Boj, 2020; Goerlandt, Li, \& Reniers, 2020; Arroyave-Cabrera, Repiso-Caballero \& González-Pardo, 2020; Mheidly \& Fares, 2020).

No obstante, la amplia gama de estudios realizados en el área de la comunicación desde el enfoque de las metrías de la información, se impone la necesidad de un estudio que represente específicamente, las particularidades de la investigación en comunicación sobre epidemias y pandemias, con el propósito de llevar a cabo una evaluación objetiva del avance experimentado, en un contexto social en el que globalmente estamos conviviendo con una pandemia, que está afectando no sólo el ámbito sanitario y social, sino también el político, económico, educativo, y por supuesto el de la comunicación.

A la luz de lo anteriormente expuesto, el objetivo de este artículo es presentar un análisis del comportamiento de la investigación en comunicación sobre epidemias y pandemias en la mayor base de datos de citas y resúmenes de literatura científica revisada por pares (Scopus).

La investigación que se propone responde a las siguientes preguntas de investigación:

P.1. ¿Cuáles son las tendencias generales de publicación en términos de producción de publicaciones?

P.2. ¿Cuáles son las regiones geográficas, países, instituciones y autores con mayor producción científica?

P.3. ¿Cuáles son las revistas y artículos portadores de conocimientos dominantes?

P.4. ¿Cuáles son los temas imperantes y su evolución temporal?

P.5. ¿Cuál es la evolución en los frentes de investigación asociados y las publicaciones clave?

\section{La comunicación del riesgo de salud durante epidemias y pandemias}

La comunicación es un campo de actividad profesional y disciplina científica (Rogers, 1994). Específicamente en el campo de la salud pública, la comunicación juega un papel fundamental en la promoción de sus objetivos básicos, incluida la prevención de enfermedades, la promoción de la salud y la calidad de vida.

La disciplina de la comunicación sanitaria existe desde la década de 1970 y es rica en teorías, paradigmas, debates y metodologías. La comunicación de riesgos es un cuerpo de teoría, investigación y práctica de la comunicación de la salud centrada específicamente en comunicar los riesgos para la salud causados por las tecnologías industriales, los peligros ambientales y naturales (incluidas las enfermedades) y las actividades humanas, entre las personas, grupos e instituciones (Glik, 2007).

El enfoque en emergencias y crisis surgió de necesidades específicas, la experiencia del SARS, los ataques de ántrax en los Estados Unidos y el mayor enfoque en el bioterrorismo llevaron a la creación de herramientas y pautas para situaciones en las que los comunicadores de salud se encontrarían como parte de una respuesta de crisis y emergencia (Veil, Reynolds, Sellnow \& Seeger, 2008; Burton-Jeangros, 2019). 
La comunicación de riesgos se originó en estudios de percepción de riesgos en la década de 1970 relacionados con los peligros potenciales para la salud y el medio ambiente de las nuevas tecnologías (Otway \& Wynne, 1989). Al igual que la promoción de la salud tradicional, la comunicación temprana de riesgos se centró en proporcionar hechos al público para que entendieran el llamado riesgo real de la misma manera que lo hicieron los expertos.

En su evolución teórico-práctica la comunicación de riesgo ha recibido la influencia de diferentes teorías, modelos y enfoques provenientes de la Sociología, la Psicología, la Economía, la Educación Social, por solo citar las más referenciadas en la literatura científica y de mayor impacto en las prácticas sanitarias orientadas a la prevención de los riesgos en salud (Gómez Castro, 2017). En este orden de ideas, la comunicación de riesgos se ha convertido en una necesidad fundamental en un mundo cada vez más convulso y, para muchos, en la medicina y la salud pública, evoca contradicciones, lo que hace que los gobiernos den la alarma y al mismo tiempo calmen los temores.

La teoría de la comunicación de riesgos se basa en las fortalezas de la promoción de la salud y la comunicación de crisis, basándose en situaciones que han involucrado una controversia más obvia y reconociendo la importancia, pero la imprevisibilidad, de los procesos sociales dinámicos que subyacen a la percepción y respuesta al riesgo (Pidgeon, Kasperson \& Slovic, 2003), de los conceptos interrelacionados de confianza, experiencia e incertidumbre (Frewer, Hunt, Brennan, Kuznesof, Ness \& Ritson, 2003; Lofstedt, 2003; Horlick-Jonesa \& Sime, 2004; Lofstedt, 2005; Thirlaway y Heggs, 2005; Alaszewski y Brown, 2007) y de las dimensiones éticas de las comunicaciones (Johnson, 1999; Guttman, 2000; Kotalik, 2005; Ulmer et al., 2007).

Durante epidemias, pandemias, desastres naturales o ambientales, el problema de la comunicación es uno de los principales temas a tratar y es esencial comunicar el riesgo sin generar alarmas y lograr una comunicación eficaz entre las personas que gestionan las emergencias. La alta tasa de mortalidad de algunas de estas enfermedades y la cobertura mediática, a veces exagerada, de su propagación ha asustado a la gente en ocasiones. Por otro lado, la comunicación de las instituciones públicas, los expertos y de los medios de comunicación ha jugado un papel importante en la presentación adecuada de los riesgos de varios brotes y en la prevención del pánico entre el público.

Las epidemias son inevitables y, a menudo, son eventos impredecibles. El entorno que rodea una epidemia es único en la salud pública. Éstas suelen estar señaladas por la incertidumbre, la confusión y una sensación de urgencia. La comunicación, realizada generalmente a través de los medios, es otra característica en torno a la epidemia. Desafortunadamente, abundan los ejemplos de la falta de comunicación que ha retrasado el control de las epidemias, socavando la confianza y el acatamiento por parte del público y prolongando innecesariamente la conmoción económica, social y política. La destreza en el campo de las comunicaciones se ha convertido en un elemento fundamental tan necesario para el control de las epidemias como el entrenamiento epidemiológico y el análisis de laboratorio. (OMS, 2005, p. 1).

La experiencia de epidemias y pandemias como el síndrome respiratorio agudo grave (SARS), síndrome respiratorio por coronavirus de Oriente Medio (MERS), influenza H1N1, H5N1, Ébola y actualmente COVID-19, muestra que la comunicación en tiempos de crisis es más eficiente si el público confía en las autoridades y los expertos competentes. Esta confianza debe construirse antes de que surja cualquier crisis proporcionando información completa, transparente y fácil de comprender sobre los riesgos y el grado actual de incertidumbre científica. Como indica Böl, (2016) "la experiencia de la epidemia de Ébola [...] muestra que la comunicación en tiempos de crisis es más eficiente si el público tiene confianza en las autoridades y expertos competentes” (p. 1).

La comunicación relacionada con los riesgos para la salud depende de la persuasión para enmarcar el mensaje que alerta al público sobre información importante y lo motiva a actuar (Lundgren \& McMakin, 2004; Laajalahti, Hyvärinen \& Vos, 2016). La comunicación de riesgos requiere un enfoque de múltiples niveles que tenga en cuenta los desarrollos tecnológicos, culturales y sociales. 
En sus inicios, la comunicación en situaciones de emergencia y brotes epidémicos fue definido por el $\mathrm{Na}$ tional Research Council, (1989) como "un proceso interactivo de intercambio de información y opinión entre personas, grupos e instituciones; suele incluir múltiples mensajes acerca de la naturaleza del riesgo o expresar preocupaciones, opiniones o reacciones acerca de los mensajes sobre el riesgo" (p. 352).

Las experiencias de emergencias sanitarias internacionales acumuladas durante el presente siglo posibilitaron abordar la comunicación de riesgo en salud como el proceso de toma de decisiones que tiene en consideración los factores políticos, sociales y económicos, analiza el riesgo como un peligro potencial a fin de formular, estudiar y comparar opciones de control con miras a seleccionar la mejor respuesta para la seguridad de la población ante un peligro probable, asigna una gran importancia al diálogo con las poblaciones afectadas y con el público interesado, para brindarles la información necesaria, que les permita tomar las mejores decisiones posibles durante una emergencia o desastre con impacto en la salud pública (OMS, 2005; OMS, 2009; Brennan y Gutiérrez, 2011).

El objetivo general de la comunicación de riesgos es proporcionar al público información significativa, relevante, precisa y oportuna en relación con los riesgos para la salud con el fin de influir en las decisiones (Health Protection Network, 2008). En el contexto de las enfermedades transmisibles, especialmente en las situaciones tensas que engendran estas enfermedades (por ejemplo, escenarios de brotes), la comunicación eficaz de riesgos es un proceso complicado y desafiante.

Un brote de enfermedad infecciosa es la aparición de una enfermedad que generalmente no se anticipa en una comunidad, región geográfica o período de tiempo en particular (Oh, Paek y Hove, 2015). Por lo general, una enfermedad infecciosa emergente implica una rápida propagación, amenazando la salud de un gran número de personas y, por lo tanto, requiere una acción urgente para detener la enfermedad a nivel comunitario (Wurz, Nurn y Ekdahl, 2013).

La comunicación de enfermedades infecciosas es un tipo de comunicación de riesgos de emergencia que es vital para la salud y la seguridad públicas (Toppenberg-Pejcic, Noyes, Allen, Alexander, Vanderford \& Gamhewage, 2019). La dificultad de la comunicación de enfermedades infecciosas surge principalmente de la gran incertidumbre sobre la ruta exacta de contaminación, tratamiento y recuperación en la etapa inicial de un brote (Lin, McCloud, Bigman y Viswanath, 2016). Es posible que no se disponga de información precisa sobre el riesgo y el tratamiento (Reynolds y Seeger, 2005).

Smith (2006) explora el papel que desempeñó la percepción del riesgo, específicamente su comunicación y gestión, en impulsar el impacto económico del $S A R S$, al margen de sus consecuencias para la salud. Concluye que la forma en que los individuos perciben el riesgo y se transmite a través de las instituciones es fundamental para las acciones tomadas, y sugiere que aunque el riesgo puede contener un elemento materialmente medible de la probabilidad de un evento, igualmente válido es el elemento socialmente construido de cómo se percibe esa probabilidad por un individuo y una sociedad. Sin embargo, estas últimas áreas están poco exploradas y subrepresentadas en la literatura teórica sobre comunicación de enfermedades infecciosas emergentes.

Freimuth, Linnan y Potter (2000) revisan la aplicabilidad de la teoría de la comunicación a problemas emergentes de enfermedades infecciosas, sugiriendo que un mensaje de prevención elaborado y difundido de manera eficaz es una medida de control clave. Se discute la importancia de informar a los grupos afectados a partir de investigaciones formativas como grupos focales, entrevistas en profundidad y datos demográficos. Saliou (1994) propone que dos tipos de información de emergencia son necesarios en caso de influenza pandémica: preventiva y reactiva.

Por tanto, de acuerdo con el planteamiento de Urbina-Medina, Noguera Brizuela, Levy Mizhary, Carrizo \& Betancourt (2016) "comunicar en un contexto de crisis o brote epidémico es un proceso 
de constante intercambio y actualización de la información con una población que, a la vez, opinará o intercambiará opinión entre s'́" (p. 114). Es un contexto excepcional en el que las autoridades sanitarias del país y locales deben tomar conciencia de la relevancia de una estrategia comunicacional efectiva, que empodere a la población de manera tal que se disminuya todo riesgo de confusión posible y de intromisión de voceros o mensajes que diversifique la respuesta y la participación social en las medidas de prevención a adoptar de acuerdo con el curso que siga una epidemia.

La comunicación de riesgos opera en un entorno de incertidumbre, los hechos sobre la situación o el evento pueden no estar claros y la base científica que sustenta las posibles respuestas puede ser imperfecta. Las enfermedades transmisibles en sí mismas son fenómenos complejos, dinámicos e inciertos, con la aparición de nuevos virus; enfermedades previamente consideradas erradicadas re-emergentes; e influenciado por la geografía, la dieta, la ocupación, el crecimiento de la población, los viajes globales y un sinnúmero de otros comportamientos y prácticas sociales y culturales (Oppong, 2009).

De modo que, las respuestas a la información sobre riesgos de epidemias y pandemias están influenciadas por factores psicológicos, sociales, culturales, de salud y socioeconómicos existentes, que afectan en gran medida la forma en que las personas interpretan las comunicaciones de riesgos para la salud, así como su voluntad y capacidad para actuar de manera oportuna. En este sentido, un aspecto importante es que la comunicación de riesgos opera con frecuencia en entornos cargados de emociones como miedo, ansiedad, desconfianza, ira, indignación, impotencia y frustración (Covello \& Sandman, 2001), reacciones comunes a los riesgos para la salud asociados con las enfermedades transmisibles.

En tales contextos, los especialistas en comunicación de riesgos destacan que las reglas habituales de comunicación a menudo se quedan cortas o pueden empeorar la situación (Covello, Peters, Wojtecki \& Hyde, 2001; Holmes, 2008). No obstante, "las comunicaciones acertadas ante una pandemia maximizan la capacidad del público para actuar como un aliado eficaz fomentando la prevención, la promoción de la contención, la resiliencia y la recuperación" (Vaughan \& Tinker, 2009, p. 324).

La comunicación es estratégica en todos los órdenes, pero aún más en tiempos de crisis sanitaria. En 2004 la OMS editó un manual sobre "Planificación de la movilización y comunicación social para la prevención y el control del dengue" (Parks \& Lloyd, 2004), donde se destacan los programas de Comunicación para el Impacto Conductual (COMBI), y básicamente se pone de manifiesto la importancia sustancial de la comunicación para promover cambios de comportamiento que lleven a minimizar riesgos, tomando como aportes los estudios de especialistas a raíz de situaciones vividas en Camboya, Colombia, República Dominicana, México, Vietnam, entre otros. Esta guía, a nivel científico de las ciencias sociales, es una orientación extensa sobre la manera en que se debe "comunicar para lograr un vínculo perfecto entre el conocimiento y la conducta, abordar los costos y valores en la adquisición de conductas saludables, determinar las etapas graduales del cambio de conducta y crear un entorno favorable" (Parks \& Lloyd, 2004, p. 145).

En la actualidad, bajo otras premisas, la situación de emergencia sanitaria a nivel mundial por la pandemia causada por la COVID-19 vuelve a centrar la mirada sobre el rol fundamental que juega la comunicación clara, concisa y coherente. Es primordial que la comunicación de salud pública sea oportuna, transparente, basada en información científica, pero también honesta y franca, mostrando empatía y comprensión sobre las preocupaciones del público. Este tipo de comunicación será esencial para garantizar que las personas comprendan los riesgos de la COVID-19 y sigan las recomendaciones de las autoridades para proteger su salud y la de todos, para lo cual se requiere profesionales formados en temas de salud y ciencia.

Es indiscutible que los medios de comunicación tradicionales constituyen un factor importante en la comunicación sobre epidemias y pandemias. También el desarrollo de la web y las herramientas basadas en la web, incluidas las herramientas de redes sociales, han jugado un papel significativo 
en los procesos de comunicación durante epidemias y pandemias y proporcionan canales valiosos para que los comunicadores lleguen al público. Las redes sociales como parte de los procesos de comunicación de riesgos también están contribuyendo a la gestión de las pandemias mismas.

La investigación emergente destaca la importancia de las redes sociales porque brindan de manera rápida una información actualizada y sin filtros (Procopio \& Procopio, 2007; Tai \& Sun, 2007) y apoyo emocional durante crisis (Macias, Hilyard \& Freimuth, 2009; Jin, Liu \& Austin, 2014). El uso de las redes sociales aumenta durante eventos de crisis (Fraustino, Liu \& Jin, 2017), y esta tendencia sigue creciendo exponencialmente (Thompson, Mazer, Payne, Jerome, Kirby \& Pfohl, 2017; Reuter \& Kaufhold, 2018; Moreno, Fuentes-Lara \& Navarro, 2020). No obstante, constituyen además, un medio veloz para la propagación de rumores, noticias falsas y por tanto desinformación (González, 2019; Moscadelli et al., 2020; Orso, Federici, Copetti, Vetrugno \& Bove, 2020; Allahverdipour, 2020; Andreu-Sánchez \& Martín-Pascual, 2020), temas y elementos que todavía necesitan ser investigados y que son objeto de estudio de la infodemiología.

\section{Metodología}

\section{Diseño de la investigación}

La presente investigación se clasifica como investigación descriptiva. Para responder a la problemática planteada combina elementos de metodología de la investigación cualitativa y cuantitativa, por lo que tiene un enfoque mixto.

Se emplean métodos y técnicas en los niveles teórico y empírico para la recogida de información. En el nivel teórico se aplican los métodos: histórico-lógico, analítico-sintético, inductivo-deductivo y sistémico-estructural. En el nivel empírico se emplea el método bibliométrico, la modelación, análisis documental a partir de la consulta de fuentes y bases de datos especializadas sobre las temáticas que se abordan y la triangulación de información como vía para validar los resultados obtenidos.

Se emplea la revisión de documentos como técnica para facilitar la localización de referentes teóricos sobre la temática en cuestión, a partir del análisis documental.

\section{Fuente de datos y estrategia de búsqueda}

Se realizó una búsqueda exhaustiva en la base de datos de Scopus (http://www.scopus.com), en la que se incluyeron todas las tipologías de publicaciones con el propósito de analizar con mayor exhaustividad la producción científica, por consiguiente, la investigación cubre el período que va desde los primeros trabajos publicados en la década de 1990 hasta septiembre de 2020, por lo que se selecciona como período de análisis 30 años, a partir de la primera publicación registrada en Scopus. Se escoge esta fuente por ser una de las bases de datos de revistas revisadas por pares más completas del mundo y por proporcionar información académica y científica de calidad (Mongeon \& Paul-Hus, 2016; Baas, Schotten, Plume, Côté \& Karimi, 2020). La estrategia de búsqueda empleada se presentó mediante la ecuación: (communication AND (epidemic OR pandemic)).

El principio que condujo a la selección de estos términos fue reflejar los contenidos más característicos del estudio e investigación de la comunicación sobre epidemias y pandemias, declaradas como tal. Para mayor precisión en la recuperación la búsqueda se realizó a través del campo de título con la intención de evitar la recuperación de registros no pertinentes. Con el propósito de evitar el sesgo estadístico por la renovación frecuente de la base de datos, toda la recuperación y la descarga de datos se completaron en un solo día, el 22 de septiembre de 2020. Se incluyen las publicaciones registradas en el 2020, a pesar de no haber concluido el año calendario, por la importancia que reviste en el tema de la actual pandemia. 


\section{Procesamiento y análisis de los datos}

Mediante la estrategia de búsqueda se recuperaron, inicialmente, 206 registros. Los metadatos de las publicaciones extraídas de la base de datos Scopus fueron los siguientes: autor, título, palabras clave, resumen, filiación, país, año y citas. Para facilitar el posterior análisis los datos fueron exportados al gestor bibliográfico Endnote X9, donde se sometieron a un proceso de normalización de metadatos y se eliminaron contribuciones duplicadas. Luego de llevar a cabo todos estos procedimientos, se realizó una revisión de contenidos y la muestra final para el análisis métrico quedó compuesta por 174 registros.

Para el análisis de los datos se utilizó el programa $R$, concretamente el paquete Bibliometrix, una herramienta de código abierto para la investigación cuantitativa en cienciometría y bibliometría, que incluye los principales métodos de análisis en el campo (Aria \& Cuccurullo, 2017; Dervis, 2019; Aria, Misuraca \& Spano, 2020). Su aplicación permitió la obtención de matrices, así como la visualización y análisis de la colaboración entre autores, países e instituciones.

Para el análisis y visualización de mapas basado en redes de co-ocurrencias de términos se usaron los títulos y los resúmenes de las publicaciones en inglés como idioma de entrada de datos, pues el programa empleado VOSviewer v1.6.15 (www.vosviewer.com) analiza el corpus con mayor precisión en inglés por ser este el idioma del desarrollo del software. El pre-procesamiento del corpus (titles \& abstract) arrojó 1163 palabras, a partir de los que se identificaron términos susceptibles de normalización usando un tesauro construido ad hoc de 153 palabras, que contenían términos topónimos y sinónimos.

Se utilizó además, el método fractional counting para el cálculo del peso de los términos (Perianes-Rodriguez, Waltman, \& Van Eck, 2016; Xie, Chen, Wang, Zheng \& Jiang, 2020). Se empleó Microsoft Excel 2019 para el procesamiento de datos, la generación de las listas de distribución de frecuencia, tablas y figuras. La información sobre los indicadores analizados y su descripción se expone en la tabla 1 .

Tabla 1. Unidades de análisis/indicadores utilizadas en el estudio.

\begin{tabular}{|c|c|c|}
\hline Dimensiones & Indicadores & Descripción \\
\hline \multirow{5}{*}{$\begin{array}{l}\text { Análisis } \\
\text { basado en } \\
\text { metadatos }\end{array}$} & $\begin{array}{l}\text { Recuento de publicaciones }(\mathrm{P}) \\
\text { por áreas temáticas }\end{array}$ & Número de artículos publicados por una temática \\
\hline & $\begin{array}{l}\text { Recuento de publicaciones }(\mathrm{P}) \\
\text { por revistas }\end{array}$ & Número de artículos publicados por una revista \\
\hline & $\begin{array}{l}\text { Recuento de publicaciones }(\mathrm{P}) \\
\text { por autor }\end{array}$ & Número de artículos publicados por un autor \\
\hline & $\begin{array}{l}\text { Recuento de publicaciones }(\mathrm{P}) \\
\text { por países }\end{array}$ & Número de artículos publicados por un país \\
\hline & $\begin{array}{l}\text { Recuento de publicaciones }(\mathrm{P}) \\
\text { por instituciones }\end{array}$ & Número de artículos publicados por una institución \\
\hline \multirow{4}{*}{$\begin{array}{l}\text { Análisis } \\
\text { basado en } \\
\text { citas }\end{array}$} & Recuento de citas por artículo & Número total de citas obtenidas por un artículo \\
\hline & Recuento de citas por revistas & Número total de citas obtenidas por una revista \\
\hline & Índice SJR & $\begin{array}{l}\text { Índice de impacto elaborado a partir de la base de datos de } \\
\text { Scopus }\end{array}$ \\
\hline & Cuartiles (Q) & $\begin{array}{l}\text { Clasificación según la posición que ocupa una revista en la/s } \\
\text { categoría/s en la/s que está indexada, atendiendo al Factor de } \\
\text { Impacto en SJR: Q1, Q2, Q3 y Q4 }\end{array}$ \\
\hline \multirow[b]{2}{*}{$\begin{array}{l}\text { Análisis } \\
\text { basado en } \\
\text { relaciones }\end{array}$} & Redes de colaboración & Análisis de las interacciones entre países, autores e instituciones \\
\hline & $\begin{array}{l}\text { Red de co-ocurrencia de } \\
\text { términos }\end{array}$ & $\begin{array}{l}\text { Frecuencia de aparición de términos y análisis de las } \\
\text { interacciones de las "palabras clave", "títulos" y "resúmenes" de } \\
\text { las publicaciones }\end{array}$ \\
\hline
\end{tabular}

Fuente: elaboración propia. 


\section{Resultados}

Se recuperaron un total de 174 publicaciones indexadas en Scopus entre 1990 y septiembre de 2020. La producción científica anual, tiene una variación creciente, 3 en la década de 1990, 31 en la del 2000 y 140 desde 2010 hasta la fecha del presente estudio, lo que muestra que el tema comenzó a ser cada vez más discutido desde 2008 , con un $87.9 \%$ producido en los últimos años y el $39.1 \%$ en el 2020 (Figura 1), con un aumento significativo en la cantidad de publicaciones científicas.

El promedio anual de publicaciones es de 5,28. A partir del coeficiente de determinación (R2) de la línea de tendencia polinómica de segundo orden, se refleja una tendencia al incremento en la cantidad de artículos relacionados con estas temáticas a publicarse en los próximos años. La mayoría de las publicaciones fueron artículos $(108 ; 62,1 \%)$, seguidos de conferencias $(16 ; 9,2 \%)$, cartas (11; $6,3 \%)$ y revisiones $(10 ; 5,7 \%)$ como tipologías documentales más representativas.

Figura 1. Tendencia de las publicaciones sobre comunicación durante epidemias y pandemias en la base de datos Scopus

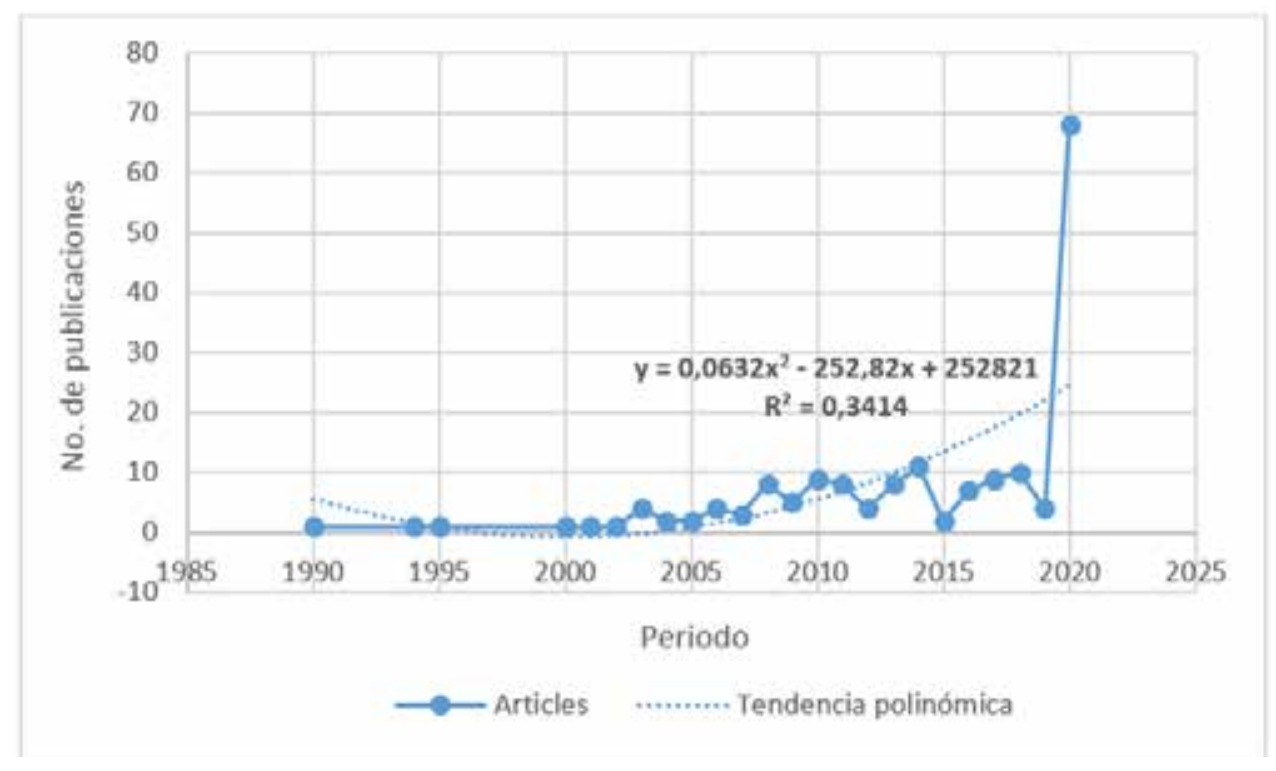

Fuente: elaboración propia.

En general, 41 países contribuyeron con resultados de investigación sobre comunicación en tiempos de epidemias y pandemias. El mapa de correlación entre países, autores e instituciones permite visualizar aquellos autores, instituciones y países que tienen un mayor número de publicaciones y la relación entre ellos (Figura 2).

Al analizar la frecuencia de publicación por países con respecto a las instituciones se obtuvo un total de 385 firmas de autores. Tres (7,3\%) países de la región de las Américas concentran el 46,2\% de las publicaciones, con Estados Unidos como país líder de la región y de la producción mundial (163; 42.3\%). Los países europeos 17 (41,5\%) representan el 22,3\% de la producción total y el Reino Unido concentra el mayor número de publicaciones del continente $(17 ; 4,4 \%)$ con la cuarta posición en el ranking mundial.

El continente asiático se encuentra representado por $(14 ; 3,6 \%)$ países con el $21 \%$ de la producción mundial y China es el país líder del continente con $(20 ; 5,2 \%)$ publicaciones y ocupa la tercera posición en el ranking mundial. Oceanía registra 2 países con $(33 ; 8,6 \%)$ publicaciones, liderado por Australia $(29 ; 7,5 \%)$ que ocupa la segunda posición en el ranking mundial y el continente africano está representado por tres países con $(7 ; 1,8 \%)$ publicaciones. 
Figura 2. Mapa de correlación entre países, autores e instituciones. Investigación en comunicación sobre epidemias y pandemias

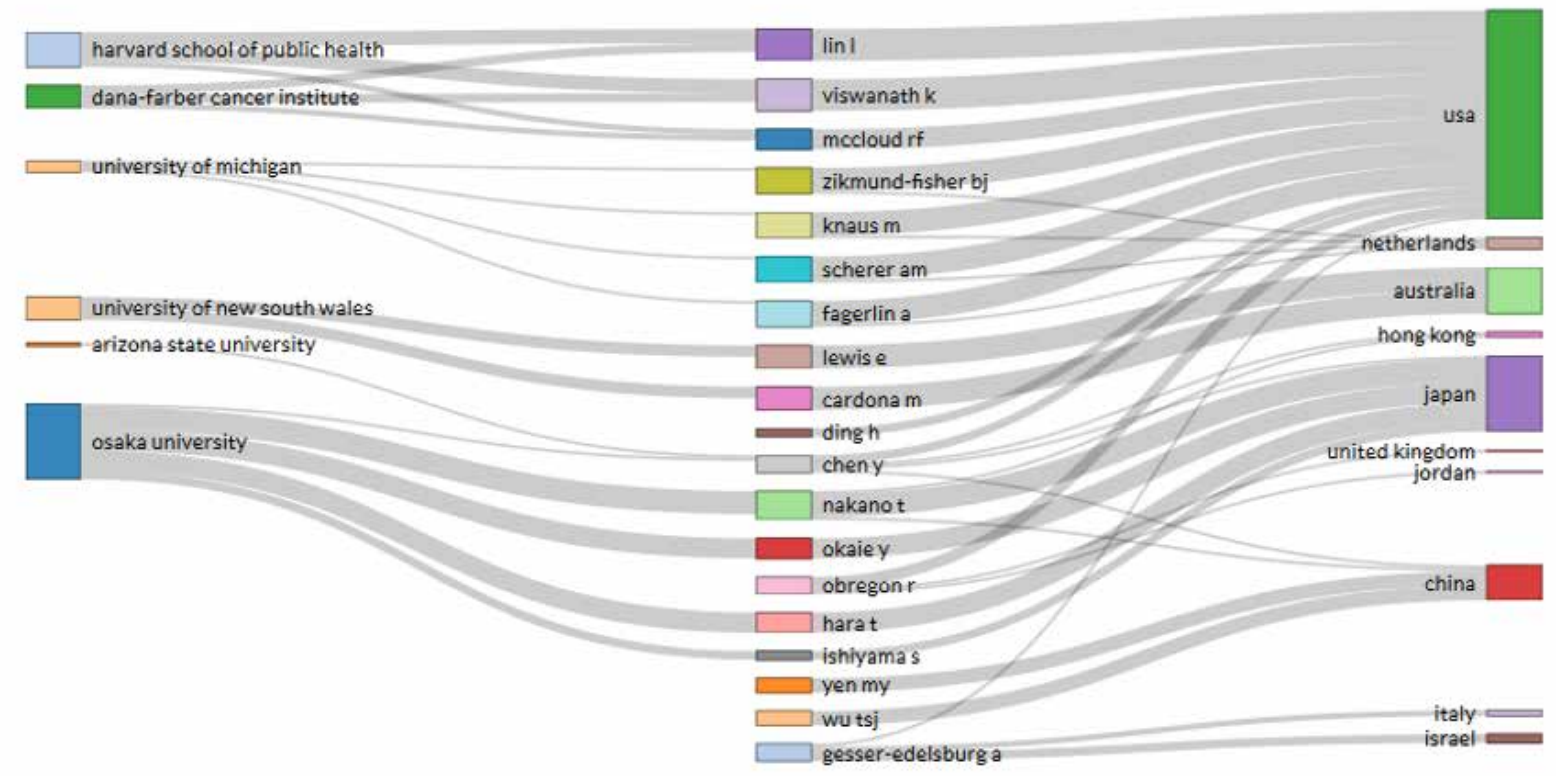

Fuente: elaboración propia.

La institución más productiva fue la Universidad de Osaka, que representó el 5,7\% $(\mathrm{N}=10)$ de todas las publicaciones, seguida por la Escuela de Salud Pública de la Universidad de Harvard con el 2,9\% (N=5). Un total de 541 autores publicaron sobre el tema. Tadashi Nakano es el autor de mayor producción científica con cinco artículos publicados y un total de 12 citas. Es profesor asociado de ingeniería en la Universidad de Osaka (Japón) y especialista en comunicación molecular.

El 33,3\% de los artículos son de autores que pertenecen al mismo país. De los países más productivos Canadá (50\%), China (25\%) y Estados Unidos (14,3\%) presentan el mayor porcentaje de colaboraciones internacionales (es decir, del total de artículos de un país el porcentaje que tienen con autores de otros países). Desde la perspectiva de la autoría, es menor la de tipo individual (41 autores publicaron trabajos individuales), por lo que predomina la autoría múltiple (el resto de las publicaciones), la media de autores por publicaciones es de 3,11 , mientras que la media de publicaciones por autores es de 0,32 . El índice de coautoría ha tenido pequeños incrementos por año en el período analizado. Esto indica una propensión al trabajo en cooperación por parte de los autores. En general se presenta un índice de colaboración de 3,91.

Los 174 artículos se publicaron en 146 revistas, y 129 revistas publicaron un solo artículo. Journal of Health Communication, Health Promotion Practice y Lecture Notes in Computer Science encabezaron la lista con un total de 5 publicaciones, seguido de las revistas Patient Education and Counseling y Plos One, con 3 publicaciones.

El número de citas (Tabla 2) varió de 232 a 31. Science (45), The Lancet (43) y Risk Analysis (43). La proporción más alta de citas por artículo fue para los Estados Unidos $(\mathrm{N}=694)$, Suecia $(\mathrm{N}=55)$ y Suiza $(\mathrm{N}=46)$. 
Tabla 2. Artículos más citados sobre comunicación y epidemias (Scopus, 1990-22 de septiembre de 2020)

\begin{tabular}{|c|c|c|c|c|}
\hline Title & Authors & Year & Journal & Citations (N) \\
\hline $\begin{array}{l}\text { Risk communication, the West Nile virus epidemic, } \\
\text { and bioterrorism: Responding to the communication } \\
\text { challenges posed by the intentional or unintentional } \\
\text { release of a pathogen in an urban setting }\end{array}$ & $\begin{array}{l}\text { Covello, V.T. } \\
\quad \text { et al. }\end{array}$ & 2001 & $\begin{array}{l}\text { Journal of Urban } \\
\text { Health }\end{array}$ & 232 \\
\hline $\begin{array}{l}\text { Effective health risk communication about pandemic } \\
\text { influenza for vulnerable populations }\end{array}$ & $\begin{array}{l}\text { Vaughan, E. \& } \\
\text { Tinker, T. }\end{array}$ & 2009 & $\begin{array}{l}\text { American Journal } \\
\text { of Public Health }\end{array}$ & 108 \\
\hline $\begin{array}{l}\text { Communication management and trust: Their role in } \\
\text { building resilience to "surprises" such as natural disas- } \\
\text { ters, pandemic flu, and terrorism }\end{array}$ & $\begin{array}{l}\text { Longstaff, } \\
\text { P.H. \& } \\
\text { Yang, S.U. }\end{array}$ & 2008 & $\begin{array}{l}\text { Ecology and } \\
\text { Society }\end{array}$ & 81 \\
\hline $\begin{array}{l}\text { Preventing the obesity epidemic by second generation } \\
\text { tailored health communication: an interdisciplinary } \\
\text { review }\end{array}$ & $\begin{array}{l}\text { Enwald, H.P. \& } \\
\text { Huotari, M.L. }\end{array}$ & 2010 & $\begin{array}{l}\text { Journal of } \\
\text { medical Internet } \\
\text { research }\end{array}$ & 78 \\
\hline $\begin{array}{l}\text { Bursty Communication Patterns Facilitate Spreading } \\
\text { in a Threshold-Based Epidemic Dynamics }\end{array}$ & $\begin{array}{l}\text { Takaguchi, T. } \\
\text { et al. }\end{array}$ & 2013 & PLoS ONE & 55 \\
\hline $\begin{array}{l}\text { The power of epidemics: Robust communication for } \\
\text { large-scale distributed systems }\end{array}$ & $\begin{array}{l}\text { Vogels, W. } \\
\text { et al. }\end{array}$ & 2003 & $\begin{array}{c}\text { Computer } \\
\text { Communication } \\
\text { Review }\end{array}$ & 53 \\
\hline $\begin{array}{l}\text { Crisis and emergency risk communication in a pan- } \\
\text { demic: a model for building capacity and resilience of } \\
\text { minority communities }\end{array}$ & $\begin{array}{l}\text { Crouse Quinn, } \\
\text { S. }\end{array}$ & 2008 & $\begin{array}{l}\text { Health promotion } \\
\text { practice }\end{array}$ & 44 \\
\hline $\begin{array}{l}\text { Effective communication during an influenza pandem- } \\
\text { ic: the value of using a crisis and emergency risk com- } \\
\text { munication framework }\end{array}$ & $\begin{array}{l}\text { Reynolds, B. \& } \\
\text { Quinn Crouse, } \\
\text { S. }\end{array}$ & 2008 & $\begin{array}{l}\text { Health promotion } \\
\text { practice }\end{array}$ & 42 \\
\hline $\begin{array}{l}\text { Rhetorics of alternative media in an emerging epi- } \\
\text { demic: SARS, censorship, and extra-institutional risk } \\
\text { communication }\end{array}$ & Ding, $\mathrm{H}$. & 2009 & $\begin{array}{l}\text { Technical } \\
\text { Communication } \\
\text { Quarterly }\end{array}$ & 40 \\
\hline $\begin{array}{l}\text { Talking about the "epidemic of the millennium": Re- } \\
\text { ligion, informal communication, and HIVIAIDS in } \\
\text { sub-Saharan Africa }\end{array}$ & $\begin{array}{l}\text { Agadjanian, } \\
\text { V. \& } \\
\text { Menjívar, C. }\end{array}$ & 2008 & Social Problems & 31 \\
\hline
\end{tabular}

Fuente: elaboración propia

Para el análisis de los términos destacados por las investigaciones, el conjunto de datos fue exportado al software VOSviewer. Del total de 1163 palabras clave, se seleccionaron las que registraban un mínimo de 10 co-ocurrencias, para cada término se calculó la puntuación de relevancia y basado en esa puntuación se seleccionaron los más relevantes para un umbral de 86 términos entre 10 y 80 coocurrencias, 2322 enlaces y una fuerza de asociación de 53100.

Las palabras claves se clasificaron en cinco clústeres en el mapa, donde el tamaño del nodo representa la proporción de la frecuencia de aparición de palabras clave, el grosor de una línea muestra la frecuencia de coocurrencia de dos términos en el mismo documento, y el color del nodo representa los diferentes clústeres (Figura 3A). Como resultado de la visualización de los términos se obtuvieron 5 grandes grupos temáticos, que configuraron los principales focos emergentes de investigación en comunicación sobre epidemias y pandemias.

El clúster 1 (conocimientos y actitudes sociales hacia la salud, en rojo) agrupó un total de 23 ítems, los términos con mayor representación fueron: female; male; adult; attitude to health; health care planning; health knowledge, attitudes, practice.

El clúster 2 (comunicación durante la pandemia COVID-19, en verde). Incluyó un total de 19 ítems, los términos con mayor representación fueron: interpersonal communication; pandemics; COVID-19; coronavirus infections; virus pneumonia; coronavirus disease 2019; betacoronavirus. 
El clúster 3 (comunicación durante la influenza A H1N1, en azul). Integró un total de 19 ítems, entre los términos con mayor peso se encuentran: communication; influenza; influenza virus A H1N1; risk communication.

El clúster 4 (comunicación de salud durante epidemias, en amarillo). Con un total de 16 ítems, destaca los siguientes términos: Humans; epidemic; medical information; disease outbreak; health communication; communicable disease control.

El clúster 5 (información epidemiológica en redes sociales, en violeta). Incluyó 9 ítems, entre los que se destacan: information dissemination; public health; epidemiology; social media; health care personnel.

En la Figura 3B, todas las palabras clave se colorearon de acuerdo con el tiempo promedio de aparición de la palabra, de azul a amarillo, lo que evidencia que los clústeres 1, 3 y 4 representan los términos con más apariciones tempranas, mientras que, los clústeres 2 y 5 evidencian los términos más recientes.

Figura 3. Mapa de coocurrencia de palabras clave en publicaciones de investigación en comunicación sobre epidemias y pandemias (A); y distribución de palabras clave según el tiempo de aparición (B).
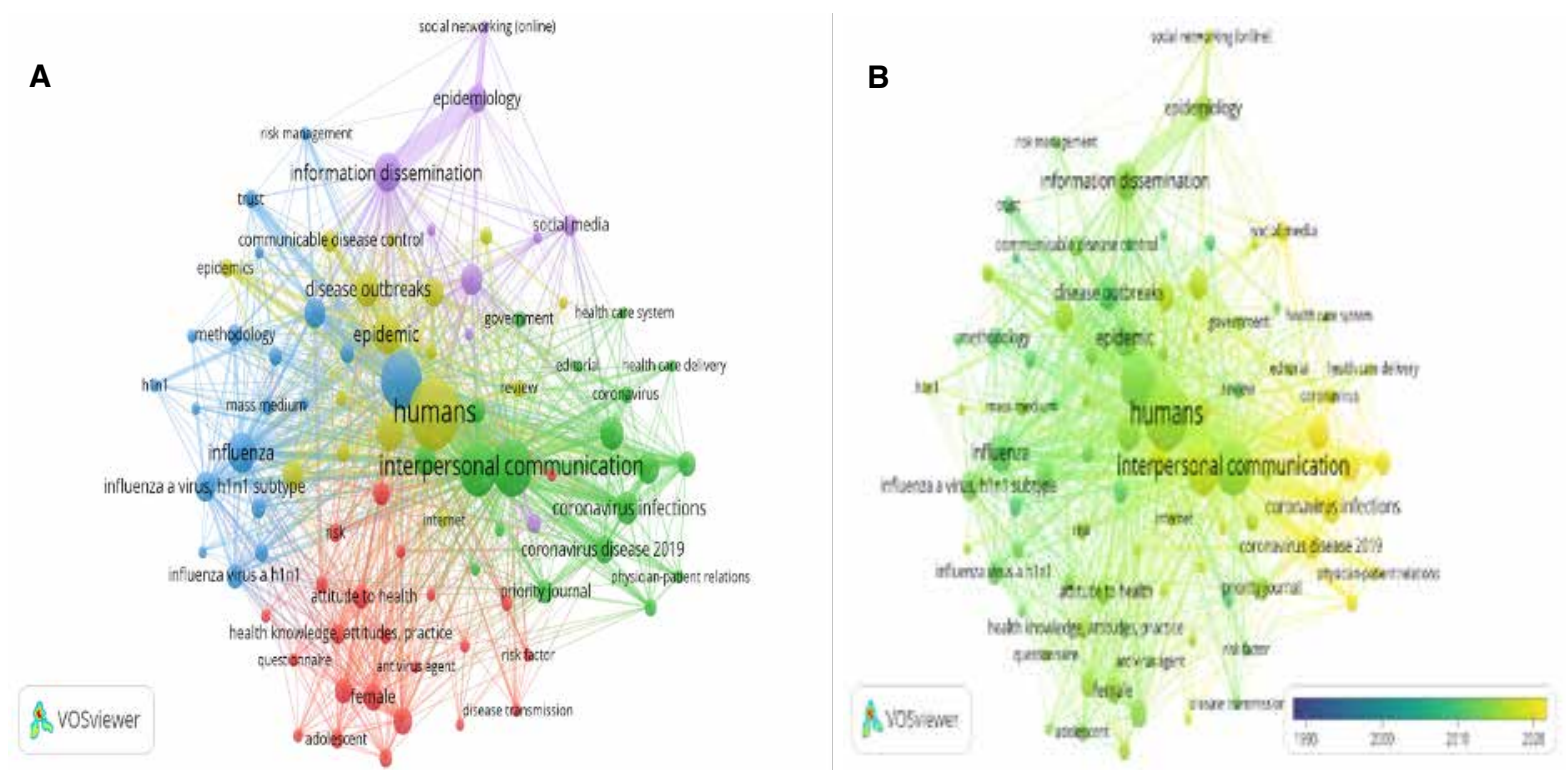

Fuente: elaboración propia

\section{Discusión}

Los análisis derivados del presente estudio revelan que el resultado de la investigación sobre comunicación y epidemias o pandemias ha fluctuado en los últimos 30 años. A raíz de los brotes epidémicos y pandemias la comunicación de riesgos de emergencia recibió un alto nivel de atención, sin embargo resulta insuficiente el tratamiento que se da a este fenómeno desde la investigación científica.

Los primeros trabajos exploraron las dificultades en la gestión de las comunicaciones de riesgos frente a la incertidumbre de epidemias y pandemias. Las investigaciones resaltan que el esfuerzo de comunicación también se ha visto dificultado por la confusión y la cacofonía en los medios de comunicación, así como las afirmaciones de expertos y políticos de todo el mundo. 
Hubo una explosión de investigación en esta área durante el período 2009-2011, no hay dudas de que este aumento es atribuible a la pandemia de gripe $A$ (H1N1) causada por una variante del Influenzavirus A (subtipo H1N1), que surgió en 2009. Durante ese desastre, se reportó un número elevado de contagios y muertes por la influenza, incluidos varios miembros del personal médico, lo que provocó un pánico masivo en todo el mundo.

Varios investigadores realizaron estudios en este campo orientados a determinar cómo la influenza pandémica puede afectar la comprensión, las necesidades de información, respuesta de las personas y ayudar a comprender cómo los esfuerzos de comunicación de riesgos pueden interactuar de manera más efectiva con las personas, antes (así como durante) un brote. Los resultados que arroja el presente estudio revelan que la investigación sobre la comunicación durante la influenza $A$ H1N1 recibió especial atención y se muestran resultados de estudios sobre el tema hasta el año 2018.

A pesar de la irrupción de virus con repercusión en todo el mundo, como VIH/SIDA, virus del Nilo Occidental, SARS-CoV-1, MERS-CoV, ébola, cólera, Chikungunya y virus del Zika, la investigación sobre comunicación y epidemias muestra un comportamiento inestable y discreto. Con el brote de SARS-CoV-2 a finales del 2019 y la declaración de pandemia a principios de 2020 la producción científica en el campo analizado alcanza sus niveles más elevados.

En cuanto a las contribuciones de regiones, países e instituciones, Estados Unidos es el líder indiscutible de la investigación sobre comunicación y epidemias; sin embargo, una institución de Japón (la Universidad Osaka) está por delante de las agencias científicas de otras regiones. Australia y China también han jugado un papel importante en la investigación. Estados Unidos parece mostrar mayor interés por la investigación sobre comunicación y epidemias, que incluye, como todo proceso de investigación, financiación adecuada, equipos avanzados e investigadores profesionales.

A pesar de que existe un predominio de la colaboración nacional, se considera aun insuficiente la cooperación entre varios países e instituciones, lo que significa que los equipos de investigación están relativamente dispersos en varias instituciones y esto reduce en gran medida la eficiencia de la investigación. El análisis de la colaboración internacional muestra que la cooperación más frecuente ocurre en los Estados Unidos, el Reino Unido y Australia.

Journal of Health Communication, Health Promotion Practice y Lecture Notes in Computer Science son las revistas líderes en estudios en esta área. Además, Science, The Lancet y Risk Analysis publicaron los artículos más citados. Por lo tanto, estos hallazgos implican que los desarrollos futuros en el campo pueden publicarse en las revistas mencionadas. Las revistas están clasificadas en el cuartil 1 y 2 de Scimago Journal and Country Rank (SJR), lo que evidencia su elevada visibilidad e impacto.

El análisis de los focos de interés y frentes emergentes en el dominio científico sobre comunicación y epidemias revela 5 áreas de investigación fundamentales. El área temática con mayor representación durante el periodo analizado está relacionada con los conocimientos, actitudes y prácticas de salud. Según las palabras clave posicionadas en este conglomerado, el frente de investigación identificado se relaciona con el análisis de los aspectos psicosociales, hábitos y conocimientos que poseen las personas con respecto a determinados brotes epidémicos y pandemias, especialmente se hace referencia al estudio de estos elementos desde la comunicación del riesgo.

La segunda área con mayor relevancia identificada se correspondió con el estudio de la comunicación durante la pandemia causada por la COVID-19. Este conglomerado se enfoca principalmente en las modalidades de comunicación de riesgos, comunicación gubernamental, estrategias para contrarrestar la infodemia, acciones para optimizar las habilidades de comunicación de los sistemas de salud con los pacientes infectados con COVID-19 y familiares. 
Se identificó otro frente de investigación, dedicado a los análisis relacionados con la comunicación de riesgo durante la pandemia de la influenza $A H 1 N 1$ y el papel de los medios de comunicación masiva. Otra área significativa investiga el papel de la información médica y la comunicación sanitaria en el control de enfermedades transmisibles en humanos y brotes epidémicos.

Por último, existen otros estudios relevantes relacionados con el papel de las herramientas digitales de comunicación, especialmente las redes sociales, en la diseminación de información epidemiológica.

El análisis de la evolución de la investigación sobre comunicación y epidemias evidenció que la investigación en este campo tomó fuerza principalmente a partir de la crisis sanitaria y de comunicación causada por la pandemia de la influenza $A H 1 N 1$, lo que sugiere que el aumento en estos estudios estuvo acompañado por la aparición de eventos de puntos críticos de investigación. El aumento de la investigación tuvo un retraso de tiempo indiscutible, lo que incide directamente en la preparación de profesionales y la población en general para hacer frente a las emergencias sanitarias con herramientas de comunicación eficaces.

La mayor producción científica se concentra en el presente año y responde a la actual pandemia causada por la COVID-19. Nunca en la historia de la humanidad se ha enfrentado una pandemia generalizada con una acción tan extensa e invasiva por parte de las autoridades políticas y la comunidad sanitaria. Sin embargo, la comunicación en torno a las medidas tomadas puede mejorarse en muchos casos y varias medidas internacionales responden a esta necesidad.

La producción científica evidencia que los medios de comunicación suelen tener una visión sensacionalista sobre la aparición reciente de un brote epidémico, o más aun de una pandemia y han sido cuestionados por exagerar o minimizar los riesgos, y contribuir a malentendidos sobre problemas epidémicos. Respuestas eficientes ante un brote, requieren de una comunicación efectiva y rápida a la comunidad, que permita actuar sin dilaciones en la detección temprana de síntomas y así evitar la diseminación de la enfermedad. "Los medios deberían ser transmisores de información científica particularmente importante para la percepción de riesgo en las epidemias". (Alfredo Duro et al., 2018, p.3).

La comunicación ha seguido su curso en un inusual entorno de confinamiento y vive una aceleración del proceso de transformación digital que ya se venía desarrollando. La crisis del coronavirus ha aumentado sustancialmente el consumo de las noticias en los medios digitales y en las redes sociales, en este entorno, la comunicación también se está adaptando, realineando los negocios y las economías, con la sociedad; analizando cómo responder cuando la crisis llega a ser el "new normal"; conociendo la nueva experiencia de la audiencia en tiempos de COVID-19 y conectando con ellos, sobre todo, atendiendo los principios claves: brindar contenidos de calidad, con la tecnología adecuada, a precios efectivos, y que conquisten a una audiencia que confía en ellos. (Zeta de Pozo, 2020; Ataguba \& Ataguba, 2020; Budhwar \& Cumming, 2020). Una situación como esta requiere una respuesta amplia e interdisciplinaria de la comunidad investigadora (Bedford, Farrar, Ihekweazu, Kang, Koopmans \& Nkengasong, 2019; Paulik, Keenan \& Durda, 2020).

En este orden de ideas, la investigación en comunicación sobre epidemias y pandemias, como subcampo del área de investigación en comunicación de riesgos, debe orientarse hacia la planificación de estrategias de comunicación que contribuyan a reducir al mínimo la perturbación generada por una epidemia o pandemia y especialmente orientadas a mitigar la desinformación como expresión de la manipulación de los medios, al control de la información en beneficio de intereses políticos o económicos y a las estrategias de gobiernos, partidos o grandes empresas para engañar a la opinión pública. 
Otra línea de investigación en comunicación debe estar enfocada en la capacitación a los diferentes profesionales de los medios de comunicación con respecto a lo que se sabe y se desconoce sobre un brote epidémico o una pandemia; así como, las medidas de prevención, de modo que, se garantice que los mensajes durante esas epidemias o pandemias sean coherentes en todos los niveles e inspiren seguridad y confianza en la ciudadanía. El reto que enfrentan los profesionales de la comunicación ante la falta de información o la manipulación de los datos es continuar informando a partir de investigaciones serias, transparentes y verificadas. Lo más importante de la comunicación en tiempos de crisis es preservar la credibilidad de quien comunica.

Otra línea de investigación que resulta necesario desarrollar desde la comunicación en tiempos de epidemias y pandemias es la relacionada con la comunicación interpersonal en modo online, especialmente en las actividades de teletrabajo y teleducación. Un fenómeno que requiere análisis además, debido a las brechas socioeconómicas y tecnológicas imperantes en la sociedad.

Es preciso indicar que entre las limitaciones del presente estudio se encuentra, en primer lugar, el uso exclusivo la base de datos Scopus, por lo que este trabajo se convierte en precursor de otras investigaciones que establecerán análisis comparativos con otras bases de datos como WoS, Dimensions, PubMed, Scielo, entre otras. También es recomendable desarrollar nuevas investigaciones métricas que aborden el impacto académico (citas) y social (altmetrics) de la investigación en comunicación sobre epidemias y pandemias.

Otra limitación del estudio se relaciona con la selección, exclusivamente, de los términos "epidemias y pandemias" para el análisis de la investigación en comunicación. Si bien, es un primer acercamiento a la investigación, ya está en curso un estudio subsiguiente orientado a describir cada una de las epidemias y pandemias de mayor impacto en la historia de la humanidad y establecer ecuaciones de búsqueda complejas para el análisis de la investigación en comunicación relacionada con esos brotes infecciosos.

\section{Conclusiones}

La presente investigación contribuye al acervo teórico sobre la producción intelectual del campo de la comunicación de riesgos de salud durante brotes epidémicos y pandemias. Examina un tema que hasta ahora ha sido objeto de estudio a nivel internacional por la significación que reviste, pero poco abordado desde las metrías de la información. Así mismo, contribuye con un aporte empírico que permite desarrollar una línea de investigación, que debe consolidarse en el ámbito internacional.

Los resultados evidencian que la publicación por países, instituciones, autores y revistas es discreta, por lo que, es un área de conocimientos que requiere mayor investigación científica y colaboración internacional. Los puntos críticos de investigación en el campo durante los 30 años registrados en la base de datos Scopus permiten inferir, que la comunicación sobre epidemias y pandemias debe convertirse en foco de la investigación en el área de comunicación de riesgos en un futuro próximo. Por lo tanto, la presente investigación puede reflejar nuevas direcciones para la investigación de la comunicación de riesgos en salud y aportar al gremio de especialistas en el área.

Cabe destacar que los resultados también pueden contribuir al debate en curso y algo polémico sobre la gestión de la comunicación durante la pandemia de la COVID-19 y si la experiencia de naciones y regiones puede ser replicada o aplicada por otros estados y culturas. Las pautas de comunicación de riesgos existentes deben fortalecer la orientación y principios sobre la mejor manera de utilizar Internet, en particular las herramientas de redes sociales como Facebook y Twitter durante los brotes de enfermedades y las crisis de salud más prolongadas. Esta es claramente un área donde se necesita desarrollar una guía basada en evidencia. 


\section{Bibliografía}

Alaszewski, A., \& Brown, P. (2007). Risk, uncertainty and knowledge. Health, Risk \& Society, 9(1), 1-10. https://doi.org/10.1080/13698570601183033

Alfredo Duro, E., Angélica Sotomayor, M., Czubaj, F., Cardozo de Martínez, C.A., Cristina Gubert , I., López Dávila, L.M., Adrián Torres, F., Benites Estupiñan, E.M., Vergès de López, C., Cudeiro, P., Rueda Castro, L. \& Sorokin, P. (2018). El impacto social de la comunicación en las epidemias: perspectivas bioéticas y de salud pública. Revista Iberoamericana de Bioética, 7, 1-16. https://doi.org/10.14422/rib.i07.y2018.007

Allahverdipour, H. (2020). Global Challenge of Health Communication: Infodemia in the Coronavirus Disease (COVID-19) Pandemic. Journal of Education and Community Health, 7(2), 65-67. https://doi.org/10.29252/jech.7.2.65

Andreu-Sánchez, C. y Martín-Pascual, M. A. (2020). Fake images of the SARS-CoV-2 coronavirus in the communication of information at the beginning of the first Covid-19 pandemic. El profesional de la información, 29(3), e290309. https://doi.org/10.3145/epi.2020.may.09

Aria, M., \& Cuccurullo, C. (2017). Bibliometrix: An R-tool for comprehensive science mapping analysis. Journal of Informetrics, 11(4):959-975. http://dx.doi.org/10.1016/j.joi.2017.08.007

Aria, M., Misuraca, M., \& Spano, M. (2020). Mapping the evolution of social research and data science on 30 years of Social Indicators Research. Social Indicators Research, 1-29. https://doi. org/10.1007/s11205-020-02281-3.

Arroyave-Cabrera, J., Repiso-Caballero, R., \& González-Pardo, R. (2020). La investigación en Comunicación en Colombia vista desde Web of Science. Revista de Comunicación, 19(2), 29-45. https://doi.org/10.26441/RC19.2-2020-A2

Ataguba, O. A. y Ataguba, J. E. (2020). Social determinants of health: the role of effective communication in the COVID-19 pandemic in developing countries. Global Health Action, 13(1):1788263. doi: 10.1080/16549716.2020.1788263.

Baas, J., Schotten, M., Plume, A., Côté, G., \& Karimi, R. (2020). Scopus as a curated, highquality bibliometric data source for academic research in quantitative science studies. Quantitative Science Studies, 1(1), 377-386. https://doi.org/10.1162/qss_a_00019

Baladrón-Pazos, A.J., Manchado-Pérez, B., \& Correyero-Ruiz, B. (2017). Estudio bibliométrico sobre la investigación en publicidad en España: temáticas, investigadores, redes y centros de producción (1980-2015). Revista Española de Documentación Científica, 40 (2): e170. doi: http:// dx.doi.org/10.3989/redc.2017.2.1411

Bedford, J., Farrar, J., Ihekweazu, C., Kang, G., Koopmans, M., \& Nkengasong, J. (2019). A new twenty-first century science for effective epidemic response. Nature 575, 130-136. https://doi. org/10.1038/s41586-019-1717-y

Bellón Saameño, J. A., \& Martínez Cañabate, T. (2001). La investigación en comunicación y salud. Una perspectiva nacional e internacional desde el análisis bibliométrico [Research into communication and health. A Spanish and international perspective through bibliometric analysis]. Atencion primaria, 27(7), 452-458. https://doi.org/10.1016/s0212-6567(01)78835-x

Böl, G. F. (2016). Risk communication in times of crisis: Pitfalls and challenges in ensuring preparedness instead of hysterics. EMBO reports, 17(1), 1-9. https://doi.org/10.15252/ embr.201541678 
Brennan, B., \& Gutiérrez, V. (2011). Guía para elaborar la estrategia de comunicación de riesgos. Washington, D.C.: OPS. http://www.paho.org/hq/index.php?option=com_docman\&task=doc view\&gid=14526\&Itemid=270\&lang=en

Budhwar, P., \& Cumming, D. (2020). New Directions in Management Research and Communication: Lessons from the COVID-19 Pandemic. British Journal of Management, 31(3):441-443. https://doi.org/10.1111/1467-8551.12426

Burton-Jeangros, C. (2019). Epidemics and risk communication: Why are lessons not learned? Managing the global health response to epidemics. New York: Routledge.

Castillo, A., \& Carretón, M.C. (2010). Investigación en Comunicación. Estudio bibliométrico de las Revistas de Comunicación en España. Comunicación y Sociedad, 23(2), 289-327.

Castillo, A., Peña, V., \& Mañas, S. (2014). Revista de Comunicación en España. Una aproximación histórica. Historia y Comunicación Social, 19, 621-630. https://doi.org/10.5209/ rev_HICS.2014.v19.45053

Covello, V. T., Peters, R., Wojtecki, J., \& Hyde, R. (2001). Risk communication, the West Nile virus epidemic, and bioterrorism: responding to the communication challenges posed by the intentional or unintentional release of a pathogen in an urban setting. Journal of Urban Health, 78(2), 382-91. https://doi.org/10.1093/jurban/78.2.382

Covello, V. T., \& Sandman, P. M. (2001). Risk communication: evolution and revolution. In A. Wolbarst (Ed.), Solutions to an environment in peril (pp.164-178). Baltimore: John Hopkins University Press.

Cummings, L. (2009). Emerging Infectious Diseases: Coping with Uncertainty. Argumentation, 23, 171-188. https://doi.org/10.1007/s10503-008-9116-9

Derviş, H. (2019). Bibliometric Analysis using Bibliometrix an R Package. Journal of Scientometric Research, 8(3), 156-160. https://doi.org/10.5530/jscires.8.3.32.

De Vries, M. S. (2016). Framing crises: response patterns to explosions in fireworks factories. Administration \& Society, 36(5), 594-614. https://doi.or/10.1177/0095399704268622

Fraustino, J. D., Liu, B. F., \& Jin, Y. (2017). Social media during disasters: A research synthesis and road map. In L. Austin \& Y. Jin, (Ed.), Social media and crisis communication (pp.283-295) New York, NY: Routledge.

Freimuth, V., Linnan, H. W., \& Potter, P. (2000). Communicating the threat of emerging infections to the public. Emerging infectious diseases, 6(4), 337-347. https://doi.org/10.3201/ eid0604.000403

Frewer, L. J., Hunt, S., Brennan, M., Kuznesof, S., Ness, M., \& Ritson, C. (2003) The views of scientific experts on how the public conceptualize uncertainty. Journal of Risk Research, 6(1), 7585. https://doi.org/10.1080/1366987032000047815

Frewer, L. J., Miles, S., Brennan, M., Kuznesof, S., Ness, M., \& Ritson, C. (2002). Public preferences for informed choice under conditions of risk uncertainty. Public Understanding of Science, 11(4), 363-372. https://doi.org/10.1088/0963-6625/11/4/304

Glik, D. C. (2007). Risk communication for public health emergencies. Annual review of public health, 28, 33-54. https://doi.org/10.1146/annurev.publhealth.28.021406.144123 
Goerlandt, F.; Li, J.; \& Reniers, G. (2020). The Landscape of Risk Communication Research: A Scientometric Analysis. International Journal of Environmental Research and Public Health, 17, 3255. https://doi.org/10.3390/ijerph17093255

Gómez Castro, L. (2017). La comunicación de riesgo en salud: aspectos teóricos y metodológicos para el control de emergencias públicas sanitarias. MEDISAN, 21(12), 33863399. http://scielo.sld.cu/scielo.php?script=sci_arttext\&pid=S1029-30192017001200013\&lng= es\&tlng $=\mathrm{es}$.

González, M. A. (2019). Fake News: desinformación en la era de la sociedad de la información. Ámbitos. Revista Internacional de Comunicación, 45, 29-52. https://doi.org/10.12795/

Ambitos.2019.145.03

Gui, X., Wang, Y., Kou, Y., Reynolds, T. L., Chen, Y., Mei, Q., \& Zheng, K. (2018).

Understanding the Patterns of Health Information Dissemination on Social Media during the Zika Outbreak. Annual Symposium proceedings. AMIA Symposium, 820-829.

Guttman, N. (2000). Public Health Communication Interventions: Values and Ethical Dilemmas. Thousand Oaks, CA: Sage Publications.

Health Protection Network. (2008). Communicating with the public about health risks. Glasgow: Health Protection Scotland.

Holmes, B.J. (2008). Communicating about emerging infectious disease: the impor-tance of research. Health, Risk \& Society, 10, 349-360. https://doi.org/10.1080/13698570802166431

Horlick-Jonesa, T., \& Sime, J. (2004). Living on the border: knowledge, risk and transdisciplinarity. Futures, 36(4), 441-456. https://doi.org/10.1016/j.futures.2003.10.006

Househ, M. (2016). Communicating Ebola through social media and electronic news media outlets: A cross-sectional study. Health informatics journal, 22(3), 470-478. https://doi. org/10.1177/1460458214568037

Hugh Feeley, T. (2008). A Bibliometric Analysis of Communication Journals from 2002 to 2005. Human Communication Research, 34(3), 505-520. https://doi.org/10.1111/j.14682958.2008.00330.x

Jin, Y., Liu, B. F., \& Austin, L. L. (2014). Examining the Role of Social Media in Effective Crisis Management: The Effects of Crisis Origin, Information Form, and Source on Publics' Crisis Responses. Communication Research, 41(1), 74-94. https://doi. org/10.1177/0093650211423918

Johnson, B. (1999). Ethical issues in risk communication: Continuing the discussion. Risk analysis, 19, 335-348. https://doi.org/10.1111/j.1539-6924.1999.tb00411.x

Jones, S., Waters, L., Holland, O., Bevins, J., \& Iverson, D. (2010). Developing pandemic communication strategies: preparation without panic. Journal of Business Research, 63(2), 126132. https://doi.org/10.1016/j.jbusres.2009.02.009

Kotalik, J. (2005). Preparing for an influenza pandemic: ethical issues. Bioethics, 19(4), 422-431. https://doi.org/10.1111/j.1467-8519.2005.00453.x

Laajalahti, Hyvärinen \& Vos. (2016). Crisis communication competence in co-producing safety with citizen groups. Social sciences, 5(1), 13. https://doi.org/10.3390/socsci5010013 
Lin, L., McCloud, R. F., Bigman, C. A., \& Viswanath, K. (2016). Tuning in and catching on? Examination of the relationship between pandemic communication and awareness and knowledge of MERS in the USA. Journal of Public Health, 39(2), 282-289. https://doi.org/10.1093/pubmed/ fdw028.

Liwei, Z., Li, H. \& Chen, K. (2020). Effective Risk Communication for Public Health Emergency: Reflection on the COVID-19 (2019-nCoV) Outbreak in Wuhan, China. Healthcare, 8(64). https:doi.org/10.3390/healthcare 8010064

Lofstedt, R. (2003). Risk communication: pitfalls and promises. European review, 11(3), 417 435. https://doi.org/10.1017/S106279870300036X

Lofstedt, R. (2005). Risk Management in Post-Trust Societies. New York: Palgrave Macmillan.

Lundgren, R., \& McMakin, A. (2004). Risk Communication: A Handbook for Communicating Environmental, Safety, and Health Risks. Columbus, OH: Battelle Press.

Macias, W., Hilyard, K., \& Freimuth, V. (2009). Blog functions as risk and crisis communication during hurricane Katrina. Journal of computer-mediated communication, 15(1), 1-31. https://doi. org/10.1111/j.1083-6101.2009.01490.x

Marí-Sáez, V., \& Ceballos-Castro, G. (2015). Análisis bibliométrico sobre "Comunicación, Desarrollo y Cambio Social” en las diez primeras revistas de Comunicación de España. Cuadernos.Info, (37), 201-212. https://doi.org/10.7764/cdi.37.828

Mheidly, N., \& Fares, J. (2020). Health communication research in the Arab world: A bibliometric analysis. Integrated Healthcare Journal, 2, e000011. https://doi.org/10.1136/ihj-2019-000011

Mongeon, P., \& Paul-Hus, A. (2016). The journal coverage of Web of Science and Scopus: a comparative analysis. Scientometrics, 106(1), 213-228. https://doi.org/10.1007/s11192-015-1765-5

Montero-Díaz, J., Cobo, M., Gutiérrez-Salcedo, M., Segado-Boj, F., \& Herrera-Viedma, E. (2018). A science mapping analysis of 'Communication' WoS subject category (1980-2013). Comunicar, 55, 81-91. https://doi.org/10.3916/C55-2018-08

Moreno, Á., Fuentes-Lara, C., \& Navarro, C. (2020). Covid-19 communication management in Spain: Exploring the effect of information-seeking behavior and message reception in public's evaluation. El profesional de la información, 29(4), e290402. https://doi.org/10.3145/epi.2020.jul.02

Moscadelli, A., Albora, G., Biamonte, M. A., Giorgetti, D., Innocenzio, M., Paoli, S., Lorini, C., Bonanni, P., \& Bonaccorsi, G. (2020). Fake News and Covid-19 in Italy: Results of a Quantitative Observational Study. International journal of environmental research and public health, 17(16), 5850. https://doi.org/10.3390/ijerph17165850

National Research Council (US). (1989). Committee on Risk Perception and Communication. Improving Risk Comunication. Washington, D.C.: National Academies Press (US).

Oh, S. H., Paek, H. J., \& Hove, T. (2015). Cognitive and emotional dimensions of perceived risk characteristics, genre-specific media effects, and risk perceptions: The case of H1N1 influenza in South Korea. Asian Journal of Communication, 25, 14-32. https://doi.org/10.1080/01292986.201 4.989240

Ophir, Y. (2018). Coverage of Epidemics in American Newspapers Through the Lens of the Crisis and Emergency Risk Communication Framework. Health security, 16(3), 147-157. https://doi. org/10.1089/hs.2017.0106 
Oppong, J. R. (2009). Globalization of communicable diseases. In R. Kitchin \& N. Thrift (Ed.), International encyclopedia of human geography (pp.209-213). Oxford: Elsevier.

Organización Mundial de la Salud. (2005). Normas de Comunicación de brotes epidémicos de la OMS. Ginebra: OMS. http://apps.who.int/iris/bitstream/10665/69370/1/WHO_CDS_2005_28_ spa.pdf?ua=1

Organización Mundial de la Salud. (2009). Preparación y respuesta ante una pandemia de influenza. Programa Mundial de la Salud. Ginebra: OMS. http://www.who.int/csr/swine_flu/ Preparacion_Pand_ESP.pdf

Orso, D., Federici, N., Copetti, R., Vetrugno, L., \& Bove, T. (2020). Infodemic and the spread of fake news in the COVID-19-era. European Journal of Emergency Medicine, 27(5), 327-328. https://doi.org/10.1097/MEJ.0000000000000713

Otway, H., \& Wynne, B. (1989). Risk Communication: Paradigm and Paradox. Risk Analysis, John Wiley \& Sons, 9(2), 141-145. https://doi.org/10.1111/j.1539-6924.1989.tb01232.x

Parks, W., \& Lloyd, L. (2004). Planificación de la movilización y comunicación social para la prevención y el control del dengue. Guía paso a paso. OMS/WMC/OPS/TDR. Ginebra: OMSOPS. https://www.who.int/tdr/publications/documents/planificacion_dengue.pdf

Parmer, J., Baur, C., Eroglu, D., Lubell, K., Prue, C., Reynolds, B., \& Weaver, J. (2016). Crisis and emergency risk messaging in mass media news stories: Is the public getting the information they need to protect their health? Health Communication, 31(10), 1215-1222. https://doi.org/10.1 080/10410236.2015.1049728

Paulik, L. B., Keenan, R. E., \& Durda, J. L. (2020). The Case for Effective Risk Communication: Lessons from a Global Pandemic. Integrated Environmental Assessment and Management, 16(5), 552-554. https://doi.org/10.1002/ieam.4312.

Perianes-Rodriguez, A., Waltman, L., \& Van Eck, N. J. (2016). Constructing bibliometric networks: A comparison between full and fractional counting. Journal of Informetrics, 10(4), 1178-1195. https://doi.org/10.1016/j.joi.2016.10.006

Pidgeon, N., Kasperson, R., \& Slovic, P. (Eds.). (2003). The Social Amplification of Risk. Cambridge: Cambridge University Press. https://doi.org/10.1017/CBO9780511550461

Procopio, C. H., \& Procopio, S. T. (2007). Do you know what it means to miss New Orleans? Internet communication, geographic community, and social capital in crisis. Journal of applied communication research, 35(1), 67-87. https://doi.org/10.1080/00909880601065722

Reuter, C., \& Kaufhold, M. A. (2018). Fifteen years of social media in emergencies: a retrospective review and future directions for crisis informatics. Journal of contingencies and crisis management, 26(1), 41-57. https://doi.org/10.1111/1468-5973.12196

Reynolds, B., \& Seeger, M. W. (2005). Crisis and emergency risk communication as an integrative model. Journal of Health Communication, 10(1), 43-55. https://doi. org/10.1080/10810730590904571

Roche, J., \& Muskavitch, M. (2003). Limited precision in print media communication of West Nile virus risks. Science Communication, 24(3), 353-365. https://doi.org/10.1177/1075547002250300

Rogers, E.M. (1994). A history of communication study: A biographical approach. Free Press. 
Saliou, P. (1994). Crisis communication in the event of a flu pandemic. European journal of epidemiology, 10, 515-517. https://doi.org/10.1007/BF01719693.

Sandell, T., Sebar, B., \& Harris, N. (2013). Framing risk: communication messages in the Australian and Swedish print media surrounding the 2009 H1N1 pandemic. Scandinavian journal of public health, 41(8), 860-865. https://doi.org/10.1177/1403494813498158

Segado-Boj, F. (2020). Research on social media and journalism (2003-2017): a bibliometric and content review. Transinformação, 32, e180096. https://doi.org/10.1590/1678$9865202032 \mathrm{e} 180096$

Smith, R. D. (2006). Responding to global infectious disease outbreaks: lessons from SARS on the role of risk perception, communication and management. Social science \& medicine (1982), 63(12), 3113-3123. https://doi.org/10.1016/j.socscimed.2006.08.004

Soós, S., \& Kiss, A. (2020). Informetrics and the study of science-society communications: a bibliometric scoping review. Scientometrics, 124, 825-842. https://doi.org/10.1007/s11192-02003444-2

Strekalova, Y. A. (2017). Health Risk Information Engagement and Amplification on Social Media. Health education \& behavior : the official publication of the Society for Public Health Education, 44(2), 332-339. https://doi.org/10.1177/1090198116660310

Tai, Z., \& Sun, T. (2007). Media dependencies in a changing media environment: The case of the 2003 SARS epidemic in China. New media \& society, 9(6), 987-1009. https://doi. org/10.1177/1461444807082691

Thirlaway, K., \& Heggs, D. A. (2005). Interpreting risk messages: Women's responses to a health story. Health Risk \& Society, 7 (2), 107-121. http://dx.doi.org/10.1080/13698570500108677

Thompson, B., Mazer, J. P., Payne, H. J., Jerome, A. M., Kirby, E. G., \& Pfohl, W. (2017). Social media and active shooter events: A school crisis communication challenge. Qualitative research reports in communication, 18(1), 8-17. https://doi.org/10.1080/17459435.2016.1247111

Toppenberg-Pejcic, D., Noyes, J., Allen, T., Alexander, N., Vanderford, M., \& Gamhewage, G. (2019). Emergency risk communication: Lessons learned from a rapid review of recent gray literature on Ebola, Zika, and yellow fever. Health Communication, 34(4), 437-455. https://doi.or $\mathrm{g} / 10.1080 / 10410236.2017 .1405488$

Ulmer, R. R., Seeger, M., \& Sellnow, T. L. (2007). Post-Crisis Communication and Renewal: Expanding the Parameters of Post-Crisis Discourse. Public Relations Review, 33(2), 130-134. https://doi.org/10.1016/j.pubrev.2006.11.015

Urbina-Medina, H., Noguera Brizuela, D., Levy Mizhary, J., Carrizo, J., \& Betancourt, A. (2016). Comunicación efectiva y ética en casos de epidemias y pandemias. Archivos Venezolanos de Puericultura y Pediatría, 79(4), 113-117.

Vaughan, E., \& Tinker, T. (2009). Effective Health Risk Communication about Pandemic Influenza for Vulnerable Populations. American Journal of Public Health, 99(S2), S324-S332. https://doi.org/10.2105/AJPH.2009.162537

Veil, S., Reynolds, B., Sellnow, T. L., \& Seeger, M. W. (2008). CERC as a theoretical framework for research and practice. Health promotion practice, 9(4 Suppl), 26S-34S. https://doi. org/10.1177/1524839908322113 
Wilder-Smith, A., Chiew, C. J., \& Lee, V. J. (2020). Can we contain the COVID-19 outbreak with the same measures as for SARS?. The Lancet. Infectious diseases, 20(5), e102-e107. https://doi. org/10.1016/S1473-3099(20)30129-8

Wurz, A., Nurn, U., \& Ekdahl, K. (2013). Enhancing the role of health communication in the prevention of infectious diseases. Journal of Health Communication, 18(2), 1566-1571. https:// doi.org/10.1080/10810730.2013.840698

Xiao, Y., Tang, S., \& Wu, J. (2015). Media impact switching surface during an infectious disease outbreak. Scientific reports, 5, 7838. https://doi.org/10.1038/srep07838

Xie, L., Chen, Z., Wang, H., Zheng, C., \& Jiang, J. (2020). Bibliometric and Visualized Analysis of Scientific Publications on Atlantoaxial Spine Surgery Based on Web of Science and VOSviewer. World neurosurgery, 137, 435-442.e4. https://doi.org/10.1016/j.wneu.2020.01.171

Zeta de Pozo, R. (2020). Editorial. Revista de Comunicación, 19(2), 5-6. https://doi.org/10.26441/ RC19.2-2020-E1 